\title{
¿HA SUPERADO ZARATUSTRA EL ESPÍRITU DE VENGANZA?
}

Did Zarathustra overcome the spirit of revenge?

\section{Carlos Gutiérrez}

Universidad Iberoamericana (México)

RESUMEN: Dos son las intenciones de este trabajo: por un lado, profundizar en la comprensión del espíritu de venganza como un concepto exclusivo de Así habló Zaratustra por hacer referencia directa al tiempo y al eterno retorno de lo mismo. Con esta comprensión ganada se revisa y critica la interpretación heideggeriana del espíritu de venganza y la pregunta por su superación.

Palabras clave: espíritu de venganza - sufrimiento - eterno retorno - superación

ABSTRACT: This article has two aims: first, to gain a deeper understanding of the spirit of revenge as a unique concept in Thus Spoke Zarathustra, being directly referred to time and to eternal recurrence. Building on this understanding, Heidegger's interpretation of the spirit of revenge is reviewed and criticized as well as the question of overcoming it.

Keywords: Spirit of revenge - Suffering - Eternal return — Overcoming

El constructo «espíritu de venganza» (Geist der Rache) aparece únicamente dos veces en toda la obra de Nietzsche, a saber en el apartado "De la redención» de la segunda parte de Así habló Zaratustra. A más de alguno le parecerá que no hay nada especial en esta unión de palabras y que puede sumarse sin mayor consideración a las ya de por sí numerosas menciones del término venganza, esparcidas por toda la obra de Nietzsche, preponderantemente para ilustrar su crítica a la moral occidental. Pero al Heidegger tardío le pareció que tal expresión rebasaba el mero plano moral para ubicarse en el terreno metafísico y que, por ello, era fundamental para entender quién es el Zaratustra de Nietzsche. Pues bien, esta contribución pretende contribuir a la comprensión de este concepto y tratará de vislumbrar una posible respuesta a la pregunta por su superación, confrontándose críticamente con la interpretación heideggeriana de Nietzsche.

\section{EL ESPÍRITU DE VENGANZA EN ASÍ HABLÓ ZARATUSTRA}

El apartado «De la redención» es el antepenúltimo de la segunda parte. Estructuralmente hablando, representa más o menos la mitad de la obra y es una especie de gozne o bisagra, pues resume lo dicho hasta ahora por Zaratustra al tiempo que anticipa, siempre de manera enigmática y misteriosa, lo que viene. Esto quiere de- 
cir que el espíritu de venganza tiene que ver con los grandes temas del pensamiento de Nietzsche, como mostraremos en seguida. En su discurso a sus discípulos, Zaratustra dice: «El espíritu de venganza: amigos míos, sobre esto es sobre lo que mejor han reflexionado los hombres hasta ahora; y donde había sufrimiento, allí debía haber siempre castigo» ${ }^{1}$.

Intentemos analizar la frase: ¿Qué quiere decir Nietzsche cuando habla del espíritu de venganza? ¿Por qué no simplemente la venganza y ya? ¿Qué agrega el espíritu a la venganza? Quiero proponer que el espíritu de venganza expresa lo mismo que la venganza en general, la cual es «un concepto diagnóstico en la filosofía moral $»^{2}$ y al mismo tiempo algo muy específico. En un primer momento el espíritu de venganza no se distingue en absoluto de otras expresiones semejantes, como el instinto de venganza, por ejemplo. En ambos casos la venganza es lo que está en el centro y los efectos son los mismos. Respecto del instinto de venganza tenemos un famoso fragmento póstumo que dice:

Durante milenios este instinto de venganza ha dominado de tal modo a la humanidad que, con su distintivo, ha marcado a la metafísica entera, a la psicología, a la concepción de la historia y, sobre todo, la moral. Por lejos que el ser humano haya llegado aunque solo sea con su pensamiento, hasta allí ha inoculado en las cosas el bacilo de la venganza ${ }^{3}$.

Y a propósito del espíritu de venganza, Carlos Vásquez ofrece una descripción detallada, la cual no deja de subrayar la dimensión moral:

¿En qué consiste ese espíritu? ¿De dónde viene y dónde hace ir? Para saber esto quizás haya que preguntar sobre qué recae. ¿Vengarse de qué? ¿Contra quién? Nietzsche dice que el espíritu de venganza es productivo, que hace cosas, que es pura acción reactiva. ¿Contra qué reacciona? Contra la vida, la tierra y cada una de sus criaturas. No crea nada, imagina, no pone nada, toma y domina. El espíritu de venganza es la vivencia más enferma. Se asocian a él la moral y los valores, la producción y el uso de la riqueza. Es un espíritu que interpreta de modo culpable. Está lleno de mala conciencia. Es un espíritu ascético y ahorrador. Es un espíritu que predica abstinencia. $\mathrm{Y}$ allí atesora y se agiganta, especula y se enriquece y vuelve famélico lo que toca ${ }^{4}$.

Así pues, en este primer momento, venganza y espíritu de venganza dicen lo mismo. ¿Por qué según Nietzsche es sobre lo que mejor se ha reflexionado hasta ahora? Porque para él la venganza ha estado presente desde siempre en la tradición occidental: desde Sócrates y hasta Schopenhauer los pensadores no han dejado de pensar desde el espíritu de venganza, determinando así todos los contenidos del pensar en general: por lo que se podría afirmar que el espíritu de venganza y la manera metafísica de pensar coinciden según Nietzsche ${ }^{5}$. Pero, para entender lo

1. Za II, «De la redención», Madrid: Alianza, 2002, p. 210.

2. Historisches Wörterbuch der Philosophie, vol. 8, p. 4.

3. KSA XIII 425 (FP IV 636).

4. C. Vásquez Tamayo, «La forma del rayo. La poética de Nietzsche en Así habló Zaratustra»: Co-herencia 3/4 (2006), p. 178.

5. Marco Parmeggiani señala acertadamente que cuando Nietzsche habla de metafísica «no se refiere a la disciplina como tal, sino a cierta forma, muy específica, de interpretar el mundo». Y más adelante: «La metafísica es, para Nietzsche, una forma específica de pensamiento que excede con mu- 
anterior, es necesario precisar y, para ello, preguntar: ¿̇en qué consiste esa venganza? Nietzsche lo expresa claramente en el fragmento citado: «allí donde había sufrimiento debía haber castigo». Cuando el ser humano experimenta el sufrimiento, busca vengarse, $\mathrm{y}$ tal venganza consiste en el castigo. Y es que para Nietzsche la vida, cuando se acepta en toda su extensión, abarca también el sufrimiento. Así lo expresa el mismo Zaratustra: «Mas todo lo que sufre, quiere vivir, para volverse maduro y alegre y anhelante» ${ }^{6}$. El sufrimiento es parte fundamental de la experiencia trágica y dionisíaca de la vida, la cual estaba aún presente en los presocráticos para ser negada, vengada, desde Sócrates en adelante. Por ello Zaratustra no puede entenderse a sí mismo sin el sufrimiento y sin defender su lugar primordial en el mundo: «Yo Zaratustra, el abogado de la vida, el abogado del sufrimiento, el abogado del círculo» ${ }^{7}$. La vida, entendiendo por tal todo lo que hay, no es tal sin sufrimiento, pues el sufrimiento es de suyo creador, el sufrimiento ayuda a la conservación y acrecentamiento de la vida misma: «la esencia del sufrimiento es anhelar más allá de sí mismo, más allá del sufrimiento» ${ }^{8}$. Pero el espíritu de venganza rechaza el sufrimiento y se venga de él por medio del castigo. Siempre tiene que haber un responsable por el sufrimiento, el cual es considerado como algo que no debería de ser. Así, se rechaza el sufrimiento y se castiga a quien lo provoque: si la multiplicidad causa sufrimiento, se le castiga con lo uno; si lo cambiante causa sufrimiento, se le castiga con lo inmutable; si el ente causa sufrimiento, se le castiga con el ser; si lo sensible causa sufrimiento, se le castiga con la idea...

Veamos ahora cómo la venganza del sufrimiento está íntimamente relacionada con los principales temas del pensar de Nietzsche.

- Espiritu de venganza, muerte de Dios y nihilismo. Eduardo Carrasco, en su comentario de Así habló Zaratustra, afirma que el tema central del segundo libro es «el sentido de la vida, el problema de cómo la vida puede ser posible si el mundo se ha despoblado de aquellos pivotes que lo sustentaban hasta hace poco" ${ }^{9}$. Esta

cho los límites de aquella disciplina que estudia el ser o las primeras causas de lo existente. Un pensamiento es metafísico no tanto por su objeto, que puede ser cualquiera, sino por la forma de pensarlo y de conocerlo» (M. Parmeggiani, Perspectivismo y subjetividad en Nietzsche, Málaga: Analecta Malacitana, 2002, pp. 41 y 47). En esta misma línea, Volkmann-Schluck dice que para Nietzsche el modo de pensar metafísico consiste en «buscar el fundamento del ente en aquella región que está más allá de la naturaleza, en la región de lo suprasensible y colocarlo como origen de lo que compone la distinción esencial del hombre: la razón pensante». Cf. K.-H. Volkmann-Schluck, Die Philosophie Nietzsches. Der Untergang der abendländischen Philosophie, Würzburg: Königshausen \& Neumann, 1991, p. 43. No obstante lo anterior, que vale de modo general para la crítica nietzscheana, Nietzsche tiene un determinado concepto de la ciencia filosófica llamada tradicionalmente metafísica: es el pensamiento que a lo condicionado añade o inventa lo incondicionado; así, la metafísica opera una inversión de la cual resulta lo condicionado a partir de lo incondicionado o bien la multiplicidad a partir de la unidad o de lo simple. Müller-Lauter señala la enorme importancia de juzgar a Nietzsche como metafísico o no desde un concepto ajeno a su pensamiento. Cf. W. Müller-Lauter, Nietzsche-Interpretationen. Band I: Über Werden und Wille zur Macht, Berlin: Walter de Gruyter, 1999, pp. 88-90.

6. Za IV «La canción del noctámbulo», Madrid: Alianza, 2002, p. 434.

7. Za III «El convaleciente», Madrid: Alianza, 2002, p. 303.

8. M. Skirl, «Leiden», en H. Ottmann (ed.), Nietzsche-Handbuch. Leben-Werk-Wirkung, Stuttgart: J. B. Metzler, 2000, p. 273.

9. E. Carrasco, Para leer Así habló Zaratustra de F. Nietzsche, Santiago de Chile: Editorial Universitaria, 2002, p. 96. 
indicación alude al hecho de la muerte de Dios o nihilismo, el cual ha sido el tema principal de la primera parte del libro. ¿Cómo vivir en un mundo abismal, en un mundo sin fundamento? La muerte de Dios y el nihilismo no son sino la constatación de que la manera metafísica de pensar se ha desmoronado. Y esta visión surgió gracias al espíritu de venganza que colocó castigo allí donde había sufrimiento. Lo originario es descrito por Nietzsche como lo trágico, donde la unidad de la realidad y el sufrimiento son siempre vividos en conjunto. La visión metafísica suprime la unidad originaria y la fragmenta en dos, dejando el sufrimiento como ligado únicamente al mundo temporal y proponiendo la felicidad como la meta del mundo verdadero. En palabras de Zaratustra: «sufrimiento fue, e impotencia, - lo que creó todos los trasmundos; y aquella breve demencia de la felicidad que solo experimenta el que más sufre de todos» ${ }^{10}$. En sus fragmentos póstumos encontramos de la manera más radical la venganza del sufrimiento como afección creadora de dos mundos:

Este mundo es aparente - por consiguiente hay un mundo verdadero. Este mundo es condicionado - por consiguiente hay un mundo incondicionado. Este mundo es contradictorio - por consiguiente hay un mundo carente de contradicción. Este mundo está en devenir - por consiguiente hay un mundo del ente... Estas inferencias son inspiradas por el sufrimiento: en el fondo son deseos de que haya un mundo así; asimismo el odio contra un mundo que hace sufrir se expresa en que se imagina otro, más valioso: el resentimiento de los metafísicos contra lo real es aquí creador ${ }^{11}$.

Un ejemplo claro del espíritu de venganza aplicado al modo metafísico de pensar es el tema de la verdad. La verdad es venganza respecto a lo aparente, a lo cambiante. Así lo afirma Nietzsche en otro de sus fragmentos póstumos:

El hombre busca «la verdad»: un mundo que no se contradiga, no engañe, no cambie, un mundo verdadero - un mundo en el que no se sufra: contradicción, engaño, cambio - icausas del sufrimiento! No duda de que haya un mundo como debe ser: quisiera buscar el camino que conduce a él ${ }^{12}$.

\section{Schüssler comenta al respecto:}

La verdad se devela como error, pero un error que es útil para la vida. Pues esta «verdad» es un medio indispensable —al menos para «el hombre más común y virtuoso", el hombre impregnado por la metafísica de las ideas- para mantenerse vivo en medio de una realidad que no es más que caos, cambio, alteración y sufrimiento ${ }^{13}$.

Si Nietzsche considera que el nihilismo no es un estadio definitivo sino que debe ser vivido de manera radical para superarlo, ya aquí se pone de manifiesto que el espíritu de venganza es algo que también busca ser superado.

10. Za I «De los trasmundanos», Madrid: Alianza, 2002, p. 61.

11. KSA XII 327 (FP IV 229).

12. KSA XII 364 (FP IV 249).

13. I. Schüssler, La question de la vérité: Thomas d'Aquin - Nietzsche - Kant - Aristote - Heidegger, Lausanne: Payot, 2001, p. 61. 
- Espiritu de venganza y superhombre. Si el superhombre es aquel que está a la altura del nihilismo, entonces el superhombre tiene que ver con el espíritu de venganza en tanto que tendrá que superarlo. En otras palabras, una caracterización clara del superhombre es su aceptación del sufrimiento sin castigos. El último hombre, es decir, el hombre, tal como ha sido concebido hasta ahora, no acepta la abundancia del sufrimiento; pero dice Nietzsche:

De este modo habla una especie de hombre que ya no se atreve a poner una voluntad, una intención, un sentido: - para toda especie sana de hombre el valor de la vida no se mide simplemente con la medida de estas cosas secundarias. Y sería posible una preponderancia del sufrimiento y, a pesar de ello, una voluntad poderosa, un decir-si a la vida, un tener-necesidad de esa preponderancia ${ }^{14}$.

Parece, pues, que una condición indispensable para la aparición del superhombre es la superación del espíritu de venganza, pues solo así habrá un hombre que soporte el sufrimiento sin quebrarse y sin buscar castigo.

Hasta aquí lo común entre el espíritu de venganza y la venganza. Ahora queremos indagar el hecho de que el espíritu de venganza sea una expresión exclusiva de Así habló Zaratustra.

- Espiritu de venganza y voluntad de poder. Si la primera parte del Zaratustra se centra en la cuestión del nihilismo, es coherente ver la voluntad de poder como tema central de la segunda parte, pues la voluntad de poder es el intento nietzscheano de vivir de acuerdo al nihilismo, ya que la voluntad quiere a partir de sí misma (no movida por un ser superior o un bien trascendente o simplemente externo) y es creadora continua de nuevas instancias de valor. Y es aquí donde Nietzsche hace la precisión respecto de la venganza al ponerla en relación directa con la voluntad y el tiempo: «Esto, sí, esto solo es la venganza misma: la aversión de la voluntad contra el tiempo y su 'fue'» ${ }^{15}$. La voluntad es voluntad de poder, la cual tiende de suyo a la conservación y el acrecentamiento de poder. La voluntad es afirmación de sí misma y, por ello, es creadora, es capaz de transvalorar los valores y de proponer siempre nuevas tablas para su acción conservadora y acrecentadora. De esto modo parece que la voluntad de poder no tiene límites y que la superación del nihilismo ha sido llevada a cabo con éxito. Pero no es así. Hay una gran roca, con la cual choca la voluntad de poder, pues no puede utilizarla para conservarse y acrecentarse, no puede utilizarla para afirmarse a sí misma. Esa roca es el tiempo y su «fue». La voluntad misma sufre al no poder querer hacia atrás y se venga contra el tiempo, pues a pesar de que ella es voluntad de poder no puede evitar ser «prisionera del tiempo, dándose cuenta con gran sufrimiento de que lo que ha pasado no puede ser deshecho» ${ }^{16}$. Karsten Harries lo explica con estas palabras:

La realidad se entiende en oposición al tiempo. Es fácil ver que lo que apoya esta profunda ilusión es lo que Nietzsche llegó a llamar el espíritu de venganza.

14. KSA XII 397-398 (FP IV 268).

15. Za II, «De la redención», Madrid: Alianza, 2002, p. 210.

16. D. Burnham y M. Jesinghausen (eds.), Nietzsche's Thus spoke Zarathustra, Edinburgh: Edinburgh UP, 2010, p. 118. 
El espíritu de venganza nos invita a pensar el ser contra el tiempo. Pero si, como está convencido de Nietzsche, la realidad y la temporalidad no pueden estar separadas, entonces una metafísica que piensa el ser en contra del tiempo, incluso cuando afirma apoderarse de la esencia de la realidad, nos tiene que alejar de la realidad ${ }^{17}$.

La realidad (que es voluntad de poder) necesita, pues, una nueva relación con el tiempo.

- Espíritu de venganza y eterno retorno de lo mismo. De manera generalizada se tiene por cierto que el tercer libro o tercera parte de Zaratustra es la cumbre de la obra por ser el lugar donde se anuncia el pensamiento abismal de Nietzsche. Pero Heidegger y otros más juzgan de vital importancia ver los signos que se anuncian ya en la segunda parte. Carrasco señala la importancia del lugar donde ocurre la acción del segundo libro. Este lugar son las islas afortunadas, las cuales poseen una característica vital: «solo Kronos reina sobre las islas», y esto significa que este lugar está "sometido únicamente al poder del tiempo»" ${ }^{18}$, esto es, que la voluntad de poder es puesta en relación con el tiempo y, por él, con el eterno retorno de lo mismo. Lo anterior sirve de marco para que algunos comentadores de Nietzsche consideren que en el apartado «De la redención» se "contiene el primer esbozo de la filosofía madura de Nietzsche sobre la historia y el tiempo» ${ }^{19}$. A través de Zaratustra, Nietzsche relaciona el nihilismo con el tiempo «y eso significa que el eterno retorno de lo mismo, que afirma exactamente esta repetición, es nihilismo» ${ }^{20}$. De esta manera el eterno retorno puede interpretarse, como el nihilismo, de dos maneras, completamente opuestas: como negación de la vida y como «retorno elegido, querido, asumido, que es, al contrario, expresión de una vida que sabe extraer del hoyo más negro y profundo del desencanto, la fuerza necesaria para superar su sufrimiento y abrirse un nuevo horizonte» ${ }^{21}$.

Quiero proponer que Nietzsche reserva la expresión espíritu de venganza a su obra principal, porque solo en ella aparece su pensamiento abismal, es decir, lo propio del espíritu de venganza es su referencia al tiempo como horizonte de la compresión del ser.

¿Contra el tiempo? ¿Qué es lo que atormenta tanto del tiempo que hace que nos queramos vengar de él? Que no podamos redimirlo del «fue». Que seamos pasajeros de su condición pasajera. No podemos evitar que pase, que se vaya al pasado. Que todo el tiempo se nos vaya y no podamos hacer nada, eso despierta nuestra sed de venganza. Somos lisiados del tiempo. No podemos reinar sobre su marcha, fugitivo. Que no seamos señores del tiempo inagotable, cúmulo de instantes eterno y fugaz, despierta nuestro resentimiento. Nos tenemos que vengar, negarlo, ponernos por encima de él. Refinamos todo nuestro poder de interpre-

17. K. Harries, Art, Love and Beauty (Lectures Notes, Spring Semester 2012), Yale University, p. 185.

18. E. Carrasco, op. cit., p. 95.

19. D. Burnham y M. Jesinghausen (eds.), op. cit., p. 118.

20. E. Carrasco, op. cit., p. 97. Leyte considera que la única tarea digna de hacerse en el tiempo de nihilismo es la de hacer una filosofía del tiempo que está más allá de la concepción metafísico-nihilista del tiempo. Cf. A. Leyte, Ensaios sobre Heidegger, Vigo: Galaxia, 1995, p. 160.

21. E. Carrasco, op. cit., p. 97. 
tación. Inventamos un todo continuo, nos vamos a vivir con el anhelo no en el tiempo sino en el sentido del tiempo ${ }^{22}$.

Me parece que con la expresión «espíritu de venganza» Nietzsche quiere llevar a cabo la crítica más radical a la manera metafísica de pensar, puesto que la venganza se dirige al tiempo y su «fue». Esta venganza fundamental contra el «fue» del tiempo ha hecho posible el pensar metafísico, pues el ser, el concepto más fundamental del pensar metafísico, se concibe desde el tiempo, a saber: se concibe como presencia (actualidad presente), haciendo irrelevante el devenir, el cambio, la multiplicidad. Por ello me parece que el único camino para pensar lo que hay de manera no metafísica, tiene que ver con una nueva manera de concebir el tiempo. Y es precisamente esto lo que intenta Nietzsche al proponer el eterno retorno de lo mismo como la lógica originaria de la voluntad de poder. Nótese que esto es exactamente el mismo intento de Heidegger en Ser y tiempo ${ }^{23}$.

Se dice que Zaratustra es el maestro que libera del espíritu de venganza para el sí al eterno retorno de lo mismo. Solo porque enseña el eterno retorno, puede ser también el maestro del superhombre. Veamos si esto se verifica.

La segunda mención del espíritu de venganza se da en un contexto amplio:

- Hasta que la voluntad creadora añada: «iPero yo lo quiero así! iYo lo querré así! ¿Ha hablado ya de ese modo? ¿Y cuándo lo hará? ¿Se ha desuncido ya la voluntad del yugo de su propia tontería? ¿Se ha convertido ya la voluntad para sí misma en un libertador y en un portador de alegría? ¿Ha olvidado el espíritu de venganza y todo rechinar de dientes? ¿Y quién le ha enseñado a ella la reconciliación con el tiempo, y algo que es superior a toda reconciliación? [...] ¿Cómo le ocurre esto? ¿Quién le ha enseñado incluso el querer hacia atrás?» 24 .

Son varios los que entienden que, en efecto, se da una liberación/redención/superación del espíritu de venganza, pues la voluntad de poder en lugar de vengarse del pasado, lo quiere y lo convierte en motivo para afirmarse nuevamente, pues lo quiere y lo querrá siempre así. Y si esto representa que se supera el espíritu de venganza, entonces se puede dejar atrás el último hombre para dar lugar al surgimiento del superhombre:

Redención en relación al superhombre es la facultad para redimir el pasado mismo en tanto que es un dominio de la voluntad afirmativa. Esto no es un cambio milagroso del pasado, o un desenredo igualmente milagroso del pasado, el presente o el futuro. Más bien, es un cambio en la relación de la voluntad con el pasado, es decir, en la imagen del pasado como lo que causa tanto dolor ${ }^{25}$.

Sin embargo, no es esto lo que Nietzsche hace decir a Zaratustra. Y no puede hacérselo decir porque el cambio no puede venir de la voluntad, no es simplemente

22. C. Vásquez Tamayo, loc. cit., pp. 178-179.

23. «La elaboración concreta de la pregunta por el sentido del 'ser' es el propósito del presente tratado. La interpretación del tiempo como horizonte de posibilidad para toda comprensión del ser en general, es su meta provisional» (M. Heidegger, Ser y tiempo, trad. J. E. Rivera, Madrid: Trotta, ${ }^{3} 2012$, p. 12).

24. Za II, «De la redención», Madrid: Alianza, 2002, p. 211.

25. D. Burnham y M. Jesinghausen (eds.), op. cit., p. 119. 
decir primero no y luego sí. El cambio de relación de la voluntad con el tiempo solo es posible si el tiempo es otra cosa, si el tiempo es algo distinto de su «fue». Y claro que se espera que la aparición del pensamiento abismal de Nietzsche venga a afirmar esta nueva concepción del tiempo. Pero después de todas las preguntas, el texto continúa de manera desconcertante:

En ese momento de su discurso ocurrió que Zaratustra se detuvo de repente, y semejaba del todo alguien que estuviese aterrorizado al máximo. [...] Mas pasado un poco de tiempo volvió a reír y dijo con voz bondadosa: «Es difícil vivir con hombres, porque callar es muy difícil. Sobre todo para un charlatán». Así habló Zaratustra ${ }^{26}$.

Nótese claramente que al final no hay respuestas, no hay afirmaciones, sino preguntas y más preguntas... y silencio... y el silencio es la voz de Zaratustra. ¿Qué quiere expresar Nietzsche con todas esas preguntas? ¿Que el asunto es visión y enigma? ¿Que él sabe la respuesta pero llega demasiado pronto y no sería entendido por sus oyentes? ¿Que el que tenga oídos para oír sabrá que la única respuesta es la que dé cada uno? De cualquier manera, me parece que Nietzsche intenta hacernos señas de por dónde se puede seguir pensando.

Lo que es cierto es que Nietzsche, a partir de la asunción del devenir como categoría filosófica fundamental, hace una crítica directa al concepto lineal (metafísico) del tiempo ${ }^{27}$, el cual es para él tan metafísico como el mundo real trascendente ${ }^{28}$. El tiempo también debe ser pensado de otra manera. Nietzsche ve el surgimiento de la problemática del tiempo en los orígenes mismos de la filosofía griega. La concepción circular del tiempo (que Nietzsche no asume sin más sino que toma en cuenta) común en el pensamiento griego, es remplazada, primeramente, por la dualidad de tiempos en Platón, quien atribuyó la eternidad al «mundo verdadero» y el tiempo lineal al «mundo aparente». Esta dualidad temporal platónica fue, a su vez, sustituida por el concepto lineal del tiempo de corte aristotélico, el cual está regido por la intencionalidad y finalidad del actuar humano, que elige medios en vistas a un fin. «Para Aristóteles, el tiempo representa, entonces, el orden mensurable del movimiento, con explícita referencia al devenir en relación con el ser» ${ }^{29}$. En esta visión aristotélica, el pasado ya no guarda importancia alguna, el presente es reducido a la mera elección de los medios, teniendo la primacía el futuro, hacia el cual se dirige teleológicamente la acción. El ser es aquello que el tiempo lineal tiene como meta, aquello que no está sujeto al devenir, sino que se mantiene ya para siempre. Contra esta visión metafísica del tiempo, Nietzsche escribe: «Lo presente no se debe justificar en modo alguno en aras de ningún futuro cualquiera o lo pasado a favor de lo presente» ${ }^{30}$.

26. Za II, «De la redención», Madrid: Alianza, 2002, p. 212.

27. Savater se pregunta: «¿Cuál es la relación de la voluntad de poder con el tiempo, si los tres estadios de este - pasado, presente y futuro- son lógicamente creaciones de aquella en su perpetua redistribución y modelación de fuerzas?» (F. Savater, Idea de Nietzsche, Barcelona: Ariel, ${ }^{5} 2003$, pp. 107-108).

28. «Las condiciones de validez y de sentido del pensamiento del retorno actúan no solamente de manera destructiva sobre los presupuestos metafísicos, ellas sustraen las condiciones a la metafísica, bajo las cuales puede en absoluto surgir y crecer» (G. Abel, Nietzsche: Die Dynamik des Willen zur Macht und die ewige Wiederkehr, Berlin: Walter de Gruyter, 1998, p. 291).

29. K. Galimberti, Nietzsche. Una guía, Buenos Aires: Nueva Visión, 2004, p. 119.

30. KSA XIII 34 (FP IV 387). 
Nietzsche quiere recuperar el devenir y su correspondiente tiempo adecuado. El devenir no concuerda con el tiempo lineal finalizador, sino con un tiempo que siempre está haciéndose presente de nuevo, cuasi regresando, y a esto Nietzsche lo llama eterno retorno. «Nietzsche no ve en el tiempo una sucesión de fines, sino aquel eterno que es la constante insurgencia de la voluntad de poder, por la que el tiempo no es das Ziel (la meta), sino Wille zur Macht (voluntad de poder)»31. Así como en el mundo metafísico la primacía ha sido del tiempo lineal teleológico, en el único mundo real, marcado por la inmanencia y la finitud, la primacía es del eterno retorno de lo mismo. El pensamiento del eterno retorno permite considerar cada momento como eterno y de esta manera se concibe la interna unidad de devenir, valor y eternidad. Y la afirmación ilimitada de esta interpretación de la realidad es la cumbre de toda consideración filosófica posible. La doctrina del eterno retorno es una fórmula ${ }^{32}$ en doble sentido: «Forma simbólica del mundo y la expresión más alta posible de la afirmación ilimitada y sin reservas de todo, incluso de la realidad más mediocre y dolorosa. En esto se presenta la superación del nihilismo» ${ }^{33}$. Aunque sea solo un atisbo, un pensamiento confusamente comunicado, Nietzsche parece afirmar la superación del espíritu de venganza.

\section{LA INTERPRETACIÓN HEIDEGGERIANA DEL ESPÍRITU DE VENGANZA}

Müller-Lauter ha llamado la atención sobre la importancia que Heidegger dio a la obra Así habló Zaratustra en las etapas finales de su interpretación de Nietzsche, a diferencia de las lecciones de los años treinta y cuarenta que se centran en los fragmentos póstumos ${ }^{34}$. En efecto, en la lección ¿Qué significa pensar? de 19511952 y en la conferencia ¿Quién es el Zaratustra de Nietzsche? de 1953 Heidegger centra su análisis del pensamiento nietzscheano en la cuestión de la superación del espíritu de venganza.

Heidegger toma para su análisis dos apartados de la segunda parte de Así habló Zaratustra. En el apartado «De las tarántulas», Heidegger llama la atención sobre la siguiente afirmación: «Pues que el hombre sea redimido de la venganza: ese es para mí el puente hacia la suprema esperanza y un arco iris después de prolongadas tempestades» ${ }^{35}$. El fragmento posee un término que llama poderosamente la atención de Heidegger: la redención de la venganza es el puente (itránsito!) hacia la suprema esperanza. Tal suprema esperanza es para Nietzsche el superhombre, para Heidegger el otro comienzo ${ }^{36}$. Las prolongadas tempestades pueden ser también interpretadas como una alusión al tiempo del nihilismo. Solo la venganza es

31. K. Galimberti, op. cit., p. 120.

32. «Fundamentalmente vale, que las fórmulas no son capaces de expresar algo general independiente del hombre... Más bien son designaciones que abrevian para aligerar nuestro trato con un acontecimiento percibido por el hombre como 'regulado'»(W. Müller-Lauter, Nietzsche-Interpretationen I, cit., p. 296).

33. G. Abel, op. cit., p. 303.

34. Cf. W. Müller-Lauter, Nietzsche-Interpretationen III: Heidegger und Nietzsche, Berlin: Walter de Gruyter, 2000, p. 135.

35. Za II, «De las tarántulas», Madrid: Alianza, 2002, p. 155.

36. Heidegger atribuye una importancia fundamental al tránsito o puente del comienzo metafísico al «otro» comienzo que, para él, es el pensar ontohistórico o pensar histórico del ser. 
nueva y no tiene, en este apartado, ningún atisbo de definición para Heidegger. En realidad, Heidegger pasa por alto que Nietzsche sí da una descripción, si no de la venganza en sí misma, sí de lo que ocasiona: «icon la venganza produce tu veneno vértigos al alma! Así os hablo en parábola a vosotros los que causáis vértigos a las almas, ivosotros los predicadores de la igualdad! $\aleph^{37}$. La venganza es el veneno de los que predican la igualdad y causa vértigo al alma. Esto será retomado más tarde.

Heidegger precisa de otro apartado para aclararse lo que Nietzsche piensa por venganza. Así, en el apartado «De la redención», encuentra lo siguiente: «El espiritu de la venganza: amigos míos, sobre esto es sobre lo que mejor han reflexionado los hombres hasta ahora; y donde había sufrimiento, allí debía haber siempre castigo» ${ }^{38}$. ¿Está aquí referida la venganza a toda la reflexión hasta ahora, a toda la historia de Occidente? ¿De la humanidad? Ciertamente, la reflexión se refiere al ente en su totalidad. Según Heidegger, el pensar ha estado determinado por el espíritu de la venganza, pero inmediatamente sale al paso de posibles interpretaciones morales o psicológicas: «Cuando Nietzsche entiende la venganza como el espíritu que entona (durchstimmt) y determina (bestimmt ${ }^{39}$ el respecto del hombre para con el ente, está pensando de antemano la venganza de un modo metafísico ${ }^{40}$.

Heidegger va a la etimología de la palabra y entonces define la venganza como una persecución que consiste en oponerse y rebajar aquello a lo que se opone para colocarse como superior delante de él. Este espíritu ha determinado el pensar metafísico desde siempre, pero puede ser aclarado más fácilmente desde la metafísica moderna, la cual define el ser como voluntad ${ }^{41}$. Ahora bien, Nietzsche entiende lo siguiente por venganza: «Esto, sí, esto solo es la venganza misma: la aversión de la voluntad con el tiempo y su 'fue'»»42. La venganza es contra un determinado respecto del tiempo: su «fue». El tiempo y su «fue» significa que el tiempo es su «fue». La venganza es contra el pasar y su carácter pasajero. «El tiempo como pasar es lo adverso de lo que sufre la voluntad» ${ }^{43}$. La aversión de la voluntad rebaja lo pasajero. Es lo que no debería de ser, lo que Platón llama mē on, lo no ente en sentido estricto, pero de alguna manera ente. La venganza extrema es la puesta de un mundo de ideales, con lo cual comparado el mundo pasajero es solo una

37. Za II, «De las tarántulas», Madrid: Alianza, 2002, p. 155.

38. Ibid., p. 210.

39. Véase que Heidegger atribuye al espíritu de venganza los verbos que ha atribuido a la experiencia y temple fundamentales de Nietzsche: «Todo pensar descansa en una experiencia fundamental. Aquello que determina (be-stimmt) el pensar, lo templa (durchstimmt) totalmente en su proveniencia y en su amplitud. Todo pensar vibra en un temple fundamental (Grund-stimmung)» (GA 50, 105).

40. M. Heidegger, «¿'Quién es el Zaratustra de Nietzsche?», en Conferencias y artículos, trad. de E. Barjau, Barcelona: Serbal, 1994, p. 108. (Se cita la página marginal que corresponde al original alemán).

41. Heidegger cita a Schelling en su ensayo sobre la libertad humana: ser como voluntad: voluntad como el ser de lo ente en su totalidad. Leibniz, Kant, Fichte, Schelling, Hegel y Schopenhauer han pensado el ser como voluntad, esto es, metafísicamente. Cf. ibid., p. 110. Vattimo señala que el espíritu de venganza está presente en toda búsqueda de responsabilidad y, sobre todo, de fundamento. Cf. G. Vattimo, Diálogo con Nietzsche, trad. de C. Revilla, Barcelona: Paidós, 2002, p. 53.

42. Za II, «De la redención», Madrid: Alianza, 2002, p. 210.

43. M. Heidegger, «¿Quién es el Zaratustra de Nietzsche?», cit., p. 112. 
apariencia, algo rebajado; en definitiva, la venganza como una negación, como un no de la voluntad a lo que deviene.

Pero la liberación del espíritu de venganza libera a la voluntad de su no y la dispone a un sí. Este sí afirma el tiempo y el pasar como es. «La liberación de la venganza es el paso de la aversión contra el tiempo a la voluntad que, al convertirse en portavoz del círculo, se representa el ente en el eterno retorno de lo mismo» ${ }^{44}$.

Y así, afirmando el devenir eternamente, puede el hombre hacer el tránsito y convertirse en superhombre. Zaratustra es el maestro que libera del espíritu de venganza para el sí al eterno retorno de lo mismo. Solo porque enseña el eterno retorno, puede ser también el maestro del superhombre, y viceversa.

$\mathrm{Al}$ parecer, Heidegger sostiene también la liberación del espíritu de venganza. Müller-Lauter comenta al respecto:

Si Heidegger se quedara en este punto, debería conceder: primero, que se da el espíritu de venganza en la historia de la metafísica occidental, el cual, segundo, es superado por Nietzsche con la liberación de la voluntad, superación que, tercero, puede ser «conservada» en el pensar ontohistórico ${ }^{45}$.

Pero no es así. Desviado por una nota al margen en un fragmento de La voluntad de poder ${ }^{46}$, Heidegger regresa a la voluntad de poder como esencia de lo ente y lo une al eterno retorno de lo mismo para hacer afirmar nuevamente a Nietzsche que solo busca el devenir permanente en el eterno retorno de lo mismo. Y se pregunta:

Este pensar, ¿̇supera la reflexión que ha estado vigente hasta ahora, supera el espíritu de venganza? ¿O bien ocurre que en este imprimir que toma a todo devenir bajo el cobijo del eterno retorno de lo mismo se está ocultando todavía una contravoluntad contra el mero pasar y con ello un espíritu de venganza extremadamente espiritualizado? ${ }^{47}$.

Esto, que podría quedar justificado como pregunta abierta, después de citar otro fragmento póstumo, alejado de la obra en cuestión ${ }^{48}$, se vuelve respuesta contundente:

¿Qué otra cosa nos queda que esto: la doctrina de Zaratustra no trae la liberación de la venganza? Lo decimos. [...] Pero lo decimos para dirigir nuestra mirada sobre el hecho de que el pensar de Nietzsche se mueve dentro del espíritu de reflexión que ha estado vigente hasta ahora. [...] Si este espíritu del pensar, tal como ha

44. Ibid., 114.

45. W. Müller-Lauter, Nietzsche-Interpretationen III, cit., p. 145.

46. «Imprimir al devenir el carácter del ser — esta es la suprema voluntad de poder», KSA XII 312 (FP IV 221). Heidegger dice que «en una observación marginal del texto, entre paréntesis, se nombra expresamente a Zaratustra». «¿Quién es el Zaratustra de Nietzsche?», cit., p. 116. Müller-Lauter señala que esa nota al margen no procede de Nietzsche sino de Peter Gast. Cf. Nietzsche-Interpretationen III, cit., p. 149 , n. 62.

47. M. Heidegger, «¿Quién es el Zaratustra de Nietzsche?», cit., p. 117.

48. «Un espíritu fortalecido por guerras y victorias, para el que la conquista, la aventura, el peligro, incluso el dolor se han convertido en necesidad; un acostumbramiento al aire cortante de las alturas, a las caminatas invernales, al hielo y a la montaña en todo sentido; una especie de sublime malicia y de insolencia última en la venganza, porque hay venganza, venganza contra la vida misma, cuando alguien que sufre profundamente toma la vida bajo su protección», KSA XII 146 (FP IV 126). 
estado vigente hasta ahora, al ser interpretado como espíritu de venganza, ha sido alcanzado en su esencia decisiva o no, es una cuestión que vamos a dejar abierta. En cualquier caso, el pensar que ha estado vigente hasta ahora es Metafísica, y presumiblemente el pensar de Nietzsche cumplimenta el acabamiento de esta ${ }^{49}$.

Así pues, el espíritu de venganza no es superado por Nietzsche según Heidegger, "pero no habla en contra de que este pensamiento, el más abismático de todos, oculte algo no pensado que, al mismo tiempo, se cierra al pensar metafísico» ${ }^{50}$. Es necesario seguir en esta dirección.

Por principio de cuentas, me parece importante rescatar lo que el propio Nietzsche coloca como característica de la venganza: «iCon la venganza produce tu veneno vértigos al alma! Así os hablo en parábola a vosotros los que causáis vértigos a las almas, ivosotros los predicadores de la igualdad! „51. Nietzsche ve con claridad que la venganza es un cierto hacer igual lo que de suyo es diferente; la venganza es imposición violenta de fijación a lo que deviene ${ }^{52}$. Me parece que esta afirmación hace insostenible la afirmación heideggeriana de que se busca nuevamente lo permanente en el eterno retorno. Nietzsche busca más bien superar el espíritu de venganza que todo lo iguala. ¿Y qué igualdad es mayor que la que hace la metafísica al decir que todo ente es; que todo es sustancia, que todo permanece a pesar del cambio? Contra esto es contra lo que Nietzsche se opone con toda energía.

Y cuando afirma que la venganza es la aversión de la voluntad contra el tiempo y su «fue», hace relación al pensamiento metafísico que busca fijar el tiempo en cuanto permanencia. A ese pensamiento, el «fue», el devenir, le causa aversión y se venga de él rebajándolo a apariencia y colocando el tiempo fijo, la eternidad como lo real y verdadero. Por eso, cuando Nietzsche afirma que la liberación del espíritu de venganza es la liberación del no de la voluntad para un sí al «fue» del tiempo, está rompiendo con el esquema metafísico del tiempo lineal y señalando una nueva manera de pensar el tiempo: la afirmación eterna de cada momento de la existencia como el instante de la decisión que cada vez el complejo de voluntades de poder tiene que tomar para mantenerse y acrecentarse a sí mismo. Y esto escapa por completo del esquema metafísico en que Heidegger lo encierra. Me parece que Nietzsche presenta con convicción la superación del espíritu de venganza: tal superación es la afirmación del devenir como tal, donde se da el ser como eterna formación de complejos de voluntades de poder en continuo círculo interpretativo, cuya lógica originaria es el eterno retorno de lo mismo. Me parece que Nietzsche entiende el tiempo como horizonte de toda posible comprensión del ser, lo cual es también el intento de Heidegger en Ser y tiempo.

El pensamiento del eterno retorno de lo mismo aparece como expresión del solamente posible (überhaupt nur mögliche) supremo interno ser-poderoso sobre la consistencia del mundo y como la superación del espíritu de venganza. [...] El pen-

49. M. Heidegger, «¿QQuién es el Zaratustra de Nietzsche?», cit., p. 118.

50. Ibid., p. 112.

51. Za II, «De las tarántulas», Madrid: Alianza, 2002, p. 155.

52. «La venganza es diagnosticada en los escritos de Nietzsche siempre de nuevo como un resorte central de metafísica dualista, en los años ochenta desde La gaya ciencia pasando por Zaratustra hasta el último periodo» (G. Abel, op. cit., p. 326). 
samiento del retorno es la más extrema piedra de toque y al mismo tiempo suprema expresión de una comprensión del mundo y de sí mismo liberada del espíritu de venganza, de una incondicional afirmación de toda realidad, de lo pasado, presente y futuro, de la historia y de la naturaleza material, del devenir y del perecer. Quien puede querer el retorno eterno idéntico de todo y cada uno, está más allá del síndrome de la venganza ${ }^{53}$.

\section{CONCLUSIONES}

Tanto Nietzsche como Heidegger llevan a una consideración diferente del tiempo, ya que en ambos el tiempo lineal se convierte en un garante metafísico tanto del conocimiento, como de la verdad y del sujeto. Nietzsche sale al paso de esa interpretación metafísica del tiempo con su doctrina y pensamiento del eterno retorno de lo mismo, mientras que Heidegger comprende el sentido del ser única y exclusivamente a partir del tiempo ${ }^{54}$. «Ambos luchan contra una concepción del tiempo que justifica y necesita un sujeto que represente la realidad de forma estable y categórica.... ${ }^{55}$. En efecto, el tiempo metafísico lineal hace que el presente sea el tiempo privilegiado, ya que en él es posible asegurar al ser como presencia presente. El pasado y el futuro pierden consistencia ontológica en relación al presente. Pero Nietzsche desenmascara la ficción metafísica de la presencia estable, pues el eterno retorno afirma la creación eterna de sentidos, lo cual por supuesto indica con claridad que no hay un sentido único y para siempre. Por su parte, Heidegger realiza su crítica al tiempo lineal de la siguiente manera:

Toda ontología que reviste los caracteres de la Vorhandenheit se caracteriza por una concepción estática del ser en la que el sujeto es su vértice último y, paralelamente, la ontología basada en el modelo de la Zuhandenheit (la analítica existenciaria) delinea el sentido del ser como tiempo, lo que equivaldría en Nietzsche a la afirmación sin fisuras del devenir ${ }^{56}$.

Así pues, quiero suscribir la afirmación de que «los dos proceden completamente de manera radical y sacuden los fundamentos de todo filosofar hasta ahora... ambos abren la perspectiva de un nuevo pensar $\aleph^{57}$. Me parece que la cuestión del tiempo señala, desde otro ángulo fundamental, la íntima afinidad

53. Ibid., pp. 344-345.

54. Leyte señala como un antecedente nietzscheano en Heidegger lo siguiente: «Existe un sentido originario de 'tiempo', que podemos llamar 'vida', 'historia', incluso 'naturaleza', anterior a cualquier oposición y división. Las diferencias dentro de este ser originario se producen de forma natural e inmediata» (A. Leyte, op. cit., p. 175).

55. M. Torres Vizcaya, «Renovación del sujeto y hermenéutica. La ausencia de Nietzsche en Sein und Zeit»: Azafea. Revista de Filosofía 7 (2005), p. 181.

56. Ibid., p. 185.

57. M. Djuric, «Nietzsche und Heidegger»: Synthesis Philosophica 4 (1987), pp. 327-350. «En efecto, nada decisivo perderíamos si supusiésemos que la historia de la metafísica se reduce, por imaginar una esquematización, a tres peldaños básicos, a saber, el platónico-aristotélico, el cartesianokantiano y, finalmente, el nietzscheano-heideggeriano» (M. Torres Vizcaya, «Del problema del conocimiento al conocimiento como problema. Una aproximación entre Ser y tiempo y El nacimiento de la tragedia»: Estudios Filosóficos 52/150 [2003], p. 309). 
entre Nietzsche y Heidegger, al mismo que puede explicar por qué a partir Ser $y$ tiempo Nietzsche se convirtió en decisión para el filósofo de Messkirch ${ }^{58}$.

\section{4. ¿ACASO OTRA POSIBILIDAD?}

Heidegger, en la lección ¿̇ué significa pensar? insinúa otra posible respuesta a la superación del espíritu de venganza. Allí escribe:

La doctrina de la fe cristiana conoce otra manera bajo la cual el «fue» puede quererse de nuevo; esa manera es el arrepentimiento [...] El hecho de que Nietzsche no tomara el camino cristiano del arrepentimiento se debe a su interpretación de lo cristiano y del cristianismo ${ }^{59}$.

Me parece que Heidegger escribe sin darse cuenta, porque él mismo tampoco hace uso de tal recurso, que el cristianismo ofrecería una superación del espíritu de venganza de una manera mucho más radical de lo que Heidegger afirma. Pues en el arrepentimiento no solo se trata de querer de nuevo el «fue», sino de vivirlo nuevamente. En el arrepentimiento hay sufrimiento sin castigo y se puede querer el momento pasado no de la misma manera (es decir: culpable) sino de una manera nueva (o sea: reconciliada). En efecto, Nietzsche plantea la misma pregunta: «¿Y quién le ha enseñado a ella [la voluntad] la reconciliación con el tiempo, y algo que es superior a toda reconciliación? ${ }^{{ }^{60}}{ }^{0}$ ¿ ¿Será que Nietzsche y Heidegger no están tan lejos del cristianismo, como lo sugiere Vattimo? ¿Será que fue el tiempo mismo, concebido como eterno retorno, quien le ha enseñado a la voluntad a reconciliarse?...

58. Al parecer, el replanteamiento de la pregunta por el ser después de Ser y tiempo tiene que ver con un nuevo acercamiento a Nietzsche. Taminiaux dice que a mitad de los años treinta Nietzsche inspiró a Heidegger para superar algunos planteamientos de la ontología fundamental por medio de una confrontación y apropiación de su pensamiento. Cf. J. Taminiaux, «On Heidegger's Interpretation of the Will to Power as Art»: New Nietzsche Studies 3 (1999), p. 17. Pöggeler señala lo siguiente: «Heidegger le comunicó a Löwith (en noviembre de 1929) que Nietzsche se había convertido para él en otoño de 1929 (cuando se presentó la crisis económica mundial) nuevamente en decisión» (O. Pöggeler, Friedrich Nietzsche und Martin Heidegger, Bonn: Bouvier, 2002, p. 11). Después del discurso del rectorado, Heidegger cree necesaria una nueva confrontación con el comienzo de la filosofía, después de la muerte de Dios. Los pensadores que le prestan ayuda en esta tarea son Nietzsche y Hölderlin. Heidegger imparte lecciones alternas sobre ambos, pero después, en 1939, cuando el fascismo se instala en Europa, Heidegger ve la asociación entre fascismo y nihilismo, y al negar el fascismo y el hitlerismo se ve obligado a negar a Nietzsche y a quedarse solo con Hölderlin.

59. M. Heidegger, ¿̇Qué significa pensar?, trad. de R. Gabás, Madrid: Trotta, 2005, pp. 69-70. De hecho, Nietzsche considera que «la moral cristiana e incluso la misma concepción cristiana del tiempo es una sola cosa con el espíritu de venganza, que es la voluntad exigiendo castigo por su incapacidad de querer hacia atrás». D. Burnham y M. Jesinghausen (eds.), op. cit., p. 119.

60. Za II, «De la redención», Madrid: Alianza, 2002, p. 211. 